\title{
Optimisation of thyroxine dose in congenital hypothyroidism
}

\section{P C Hindmarsh}

\section{Optimum initial dosage remains unclear}

$\mathrm{T}$ he introduction of the screening programme for congenital hypothyroidism in the late 1970s and early 1980s has been rightly hailed as a major success in the prevention of neurological handicap. With a prevalence of between $1 / 3000$ and $1 / 5000$ live births, congenital hypothyroidism is by far the commonest metabolic disorder leading to neurological handicap; given the inexpensive nature of assays for thyroid stimulating hormone (TSH) and thyroxine treatment, its cost effectiveness must be beyond doubt. The improvement in outcome from intervention with thyroxine at an earlier stage than was hitherto possible, meant that for the majority of children treated with severe congenital hypothyroidism a near normal intelligence quotient (IQ) might be expected. Early reports tended to confirm this view, although a long term perspective suggests that there remain significant areas of cognitive deficit, particularly in visuospatial tasks, attention, and to a certain extent memory. ${ }^{1-3}$

In addressing some of these issues several groups have suggested that early diagnosis combined with high thyroxine dosing can reverse this deficit and normalise IQ.

\section{OUTCOMES OF CURRENT INTERVENTION}

Neonatal screening and early replacement therapy with thyroxine has transformed the outlook for moderately affected (presenting total serum thyroxine concentrations greater than $40 \mathrm{nmol} / \mathrm{l}$ or presenting free thyroxine concentration greater than $5.5 \mathrm{pmol} / \mathrm{l}$ ) individuals, normalising IQ at 5 and 10 years of age. Severely affected infants (presenting thyroxine less than $40 \mathrm{nmol} / \mathrm{l}$ ), approximately $50 \%$ of the total, still develop a significant IQ deficit of approximately 10 points and may need special education. ${ }^{45}$ This may be related to hypothyroidism in utero, but several studies using higher doses of thyroxine in infancy in an uncontrolled manner have suggested that the effects of severe congenital hypothyroidism could be mitigated. ${ }^{67}$

There are a number of problems associated with this approach. These largely relate to developmental outcomes reported with different starting doses of thyroxine and inclusion of a wide range of disease severity. Furthermore, there are no reports of randomised controlled trials addressing these issues, which makes it difficult to dissect the balance between benefit and potential problems. Our group has recently conducted a systematic review of the literature, which highlights the problems associated with the interpretation of the dosing studies. ${ }^{8}$ Of the 1271 papers identified, 14 met the search criteria based on statement of starting dose and assessment of development. In four comparative studies, ${ }^{5-12}$ (560 patients) there was no consistent effect of starting dose of thyroxine; one study suggested higher doses led to more behavioural problems at a later age. ${ }^{12}$ The variability in the classification of the disease severity, lack of adjustment for socioeconomic group and parental IQ, and doses actually used made metaanalysis difficult. This is in addition to more general problems, such as confounding secular trends in IQ score, ${ }^{13}$ differential loss to follow up, the type of children refusing to participate, and how the assessment instruments were administered. The overall conclusion from this systematic review was suggestive and supportive of the concept that timing and dose may have a role in cognitive development, but the results of studies conducted to date are inconsistent and could not be considered conclusive.

Furthermore, none of the studies have addressed higher order skills; normalisation of IQ may not be the only goal and may distract attention from identifying more specific learning difficulties. In addition, consideration needs to be given not only to the potential benefits of higher dosing schedule but also to potential long term adverse effects. From the North American series there is a suggestion in the assessment at 7 years of age that the improvement in IQ was bought at the expense of poor attention, poor memory, and deterioration in social behaviour. If this were to be the case then the savings made in the educational sector from normalisation of IQ may not be realised if expenditure is required to address these needs. Other issues in thy- roxine dosing need to be addressed, such as the longer term effect of using high doses of thyroxine on bone mineral density.

The optimal initial thyroxine dose for children with severe congenital hypothyroidism remains, therefore, unclear. In the UK the dosing schedule has ranged from about $6 \mu \mathrm{g} / \mathrm{kg} /$ day up to the currently used schedule of about 8-9 $\mu \mathrm{g} / \mathrm{kg} /$ day, which is not too different from that used in Canada. The high dosing schedules take the dose up to 12-15 $\mu \mathrm{g} / \mathrm{kg} / \mathrm{day}$. There has been a suggestion that by using these higher doses the serum thyroxine concentration is normalised quicker (eight days), ${ }^{14}$ although the evidence that this has any effect on intellectual outcome is poor. An alternative approach suggested is to combine thyroxine replacement with the more biologically active form triiodothyronine. Such an approach has been advocated for the management of adults with acquired hypothyroidism. ${ }^{15}$ This approach has support from the point of view of effects of triiodothyronine on peripheral tissues, but it has to be remembered that as far as the brain is concerned it is the deiodination of thyroxine within the neurones to triiodothyronine that is required. Simply giving triiodothyronine would not assist this process, as access to the target tissue-in this case the brain-would not be improved.

\section{MONITORING OF THERAPY}

Monitoring the replacement of thyroxine requires careful assessment of anthropometric measures (height and weight), and regular measurements of serum free thyroxine, free triiodothyronine, and TSH concentrations. These measures need to be made fairly frequently during the first six months of life, not only because growth and change in body size is at its most rapid, but also because this is a critical time period for ongoing dendritic formation and neurological development. A suggested regimen is for samples to be taken at fortnightly intervals for the first month of life, monthly for the next three months, six weekly until 6 months, and three monthly thereafter to 1 year of age. At that point the follow up regimen can be relaxed to perhaps six monthly visits.

While anthropometric aims are clear (normal height and weight gain), it is difficult to be sure what should be the main aim of biochemical monitoring. There are two possibilities. The first is to maintain a serum free thyroxine concentration in the upper half of the normal range and not to worry too much about what happens to the circulating serum TSH concentration. A number of studies show that serum TSH concentrations in patients with congenital hypothyroidism do not behave in 
the same manner that we would expect with acquired hypothyroidism. A gradual decline of serum TSH concentrations, even in the face of normalisation of the circulating serum free thyroxine concentrations, can often be encountered in patients with congenital hypothyroidism. Serum TSH concentrations within the normal range can be observed by 6 months of age, but persistent elevations in about $10 \%$ of those treated can be noted up to 3 years of age. ${ }^{16}$ The response to this could be to give more thyroxine; the danger is over treating the individual, which may in itself have deleterious effects on overall development. The second approach to the problem is to move to rapid normalisation of serum TSH concentrations on the basis that they reflect what the neurones are being exposed to with respect to ambient thyroxine concentration. This assumes that the dose-response curves of hypothalamopituitary and neuronal tissues are similar, which may not be the case.

This elevation of serum TSH concentrations, with serum free thyroxine concentrations within the normal range $\mathrm{e}^{16-18}$ has been attributed to suboptimal therapy or a reset thyroxine feedback mechanism. ${ }^{18}{ }^{19}$ In patients with acquired hypothyroidism who are on thyroxine therapy and have normal serum concentrations of free thyroxine yet raised TSH concentrations, the question of compliance with therapy is always raised. The situation may not be the same, however, in congenital hypothyroidism because of the altered feedback. Evidence to support the latter is: augmented prolactin responses to exogenous thyrotrophin releasing hormone $(\mathrm{TRH})^{20}$; the need for large doses of exogenous thyroxine to block the TSH response to TRH in adults with treated congenital hypothyroidism $^{21}$; and the permanent resetting of thyroxine feedback in rodents who were transiently hypothyroid in the neonatal period. ${ }^{22}$ However, the situation is likely to be even more complex as the mechanisms involved in setpoint maturation involve hypothalamic TRH secretion, pituitary TRH receptors, thyrotroph triiodothyronine nuclear receptors and cofactors, thyrotroph monodeiodinase activity, and TSH biosynthetic and secretory mechanisms

\section{FACTORS INFLUENCING THYROXINE BIOAVAILABILITY}

A number of factors have been identified which influence thyroxine bioavailability (see table 1). Given the serious nature of the condition and the fact that administration of medication is in the hands of a parent, the question of compliance with therapy is perhaps less of an issue than it might be in later years. The actual bioavailability of thyroxine following oral administration is approximately

\section{Table 1 Bioavailability of} thyroxine

Thyroxine formulation

Severity of hypothyroidism

Maturity of hepatic glucoronidation

Metabolic clearance rate

Infant formulas

Iron supplements

$81 \%$. One of the simplest ways in which this can be altered is in terms of the type of thyroxine used. Thyroxine is not dispensed as a solution, but is often made up by crushing tablets and suspending them for administration. The danger of this approach is that unless adequate mixing of the suspension takes place, it is quite likely that the individual will be under dosed for part of the time and then overdosed. Given the limited range of thyroxine tablets currently available in the UK, this approach is understandable but not sustainable. Tablet sizes are 25,50 , and $100 \mu \mathrm{g}$, so intermediate doses of $12.5 \mu \mathrm{g}$ increments are achievable and often sufficient from the clinical standpoint. Hepatic glucorinadation may well influence handling of thyroxine in the first few weeks of life, particularly in the congenital hypothyroid child who is born premature. Infant formulas, especially those that contain soya products, may influence thyroxine bioavailability. In the 1950s and 1960s, soya milk products were associated with alterations in thyroxine metabolism. ${ }^{23}$ Major changes to the formulation took place during the 1960s, so that hypothyroidism associated with ingestion of these products effectively disappeared. However, it is possible that in patients that are heavily dependent on soya based feeds and who are receiving a fixed exogenous dose of thyroxine, problems may be encountered as a result of alterations in thyroxine bioavailability (less thyroxine via the enterohepatic circulation and altered thyroid binding globulin concentrations). ${ }^{24}$ Hence careful attention needs to be paid to the diet in these individuals, and an increase in thyroxine dosing may be necessary to compensate for these changes.

\section{CONCLUSIONS}

The optimal initial thyroxine dose for infants with congenital hypothyroidism remains unclear. The question of whether high dose replacement therapy is more effective than standard dose in reversing the IQ deficit in patients with severe congenital hypothyroidism, without detrimental effects on behaviour, poor attention, poor memory, and deterioration in social behaviour remains unanswered. If IQ were to be improved by an increased dose at the expense of poor attention, poor memory, and a deterioration in social behaviour, the need for special schooling might not be lessened. These issues cannot be resolved by retrospective analysis nor by some of the studies that are currently proposed, because none address the issue of higher order cognitive skills. The detailed evaluation and neuropsychological development programmes now available allow a thorough assessment of these skills; the executive functions of the prefrontal cortex can be assessed. More precise information on the effect of dose might be obtained from individual patient data meta-analysis of the available cohort data. Alternatively, it would seem more sensible, given the equipoise that exists within the paediatric community within the UK, to consider the possibility of conducting a prospective double blind randomised controlled study to assess the issues of benefits and safety which will allow definitive statements to be made.

Arch Dis Child 2002;86:73-75

\section{Authors' affiliations}

P C Hindmarsh, London Centre for Paediatric Endocrinology and Metabolism, Cobbold Laboratories, Middlesex Hospital, Mortimer Street, London WIT 3AA, UK

Correspondence to: P C Hindmarsh (p.hindmarsh@ucl.ac.uk)

\section{REFERENCES}

1 Hulse JA. Outcome for congenital hypothyroidism. Arch Dis Child 1984;59:23-30.

2 Klein AH, Meltzer S, Kenny FM. Improved prognosis in congenital hypothyroidism treated before age three months. J Pediatr 1972;81:912-15.

3 Rovet JF. Congenital hypothyroidism: psychometric outcome [abstract S22-3]. 83rd Annual Meeting of the Endocrine Society, 2001.

4 Derksen-Lubsen G, Verkerk PH. Neurological development in early treated congenital hypothyroidism: analysis of literature data. Pediatr Res 1996;39:561-6.

5 Tillotson SL, Fuggle PW, Smith I, et al. Relation between biochemical severity and intelligence in early treated congenital hypothyroidism: a threshold effect. $B M$ 1994;309:440-5.

6 Grüters A, Liesenkotter KP, Zapico M, et al. Results of the screening program for congenital hypothyroidism in Berlin (1978-1995). Exp Clin Endocrinol Diabetes 1997; 105:28-31.

7 Germak JA, Foley TP Jr. Longitudinal assessment of L-thyroxine therapy for congenital hypothyroidism. J Pediatr 1990;117:211-19.

8 Hrytsiuk I, Gilbert R, Logan S, Brook CGD. Starting dose of levothyroxine for the treatment of congenital hypothyroidism: a systematic review. J Pediatr. Submitted (unpublished copy available from cebch@ich.ucl.ac.uk).

9 Rovet JF, Ehrlich RM. Long-term effects of L-thyroxine therapy for congenital hypothyroidism. J Pediatr 1995;126:380-6.

10 Heyerdahl S. Treatment variables as predictors of intellectual outcome in children with congenital hypothyroidism. Eur J Pediatr 1996;155:357-61.

11 Bongers-Schokking JJ, Koot HM, Wirsma $D$, et al. Influence of timing and dose of thyroid hormone replacement on development in infants with congenital hypothyroidism. J Pediatr 2000;136:292-7. 
12 Rovet JF, Ehrlich RM. Psychoeducational outcome in children with early-treated congenital hypothyroidism. Pediatrics 2000;105:515-22.

13 Flynn JR. Massive IQ gain in 14 nations: what $I Q$ tests really measure. Psychol Bull 1987;101:171-91.

14 Bongers-Schokking JJ, de Muinck Keizer-Schrama SM, Koot HM. Congenital hypothyroidism: effect of time of onset and initial thyroxine dose on outcome [abstract S22-2]. 83rd Annual Meeting of the Endocrine Society, 2001.

15 Bunevicius R, Kazanavicius G, Zalinkevicius $R$, Prange AJ. Effects of thyroxine as compared with thyroxine plus triiodothyronine in patients with hypothyroidism. N Engl J Med 1999;340:424-9.

16 Fisher DA, Schoen EJ, La Franchi S, et al. The hypothalamic-pituitary-thyroid negative feedback control axis in children with treated congenital hypothyroidism. J Clin Endocrinol Metab 2000;85:2722-7.

17 Raza J, Hindmarsh PC, Brook CGD. Factors involved in the rate of fall of thyroid stimulating hormone in treated hypothyroidism. Arch Dis Child 1997;77:526-7.

18 Grant DB. Monitoring TSH concentrations during treatment for congenital hypothyroidism. Arch Dis Child 1991;66:669-70.

19 Heyerdahl S, Kase BF. Significance of elevated serum thyrotrophin during treatment of congenital hypothyroidism. Acta Paediatr 1995:84:634-8

20 Sack J, Shafrir Y, Urbach D, Amado AO. Thyroid stimulating hormone, prolactin and growth hormone responses to thyrotropin releasing hormone in treated children with congenital hypothyroidism. Pediatr Res $1985 \cdot 19 \cdot 1037-9$.

21 Cavaliere H, Medeiros-Neto GA, Rosner W, Kourides IA. Persistent pituitary resistance to thyroid hormone in congenital vs late onset hypothyroidism. J Endocrinol Invest $1985 \cdot 8 \cdot 527-32$

22 Bakke JL, Lawrence NL, Bennett J, Robinson $\mathrm{S}$. Endocrine syndromes produced by neonatal hyperthyroidism, hypothyroidism or altered nutrition and effects seen in untreated progeny. In: Fisher DA, Burrow GN, eds. Perinatal thyroid physiology and disease. New York: Raven Press, 1975:79-116.

23 Labib M, Gama R, Wright J, et al. Dietary maladvice as a cause of hypothyroidism and short stature. BM 1989;298:232-3

24 Calman K. Chief Medical Officer. Phytoestrogens in soya infant formula milk. London: Department of Health, 1996 (CEM/CMO/96/98).

\section{STAMPS IN PAEDIATRICS}

\section{Children's Day}

The 14 November is celebrated in India as Children's Day, in memory of Pandit Jawaharlal Nehru's birthday. Nehru (1889-1964) was the first prime minister of Independent India and was called "chacha Nehru" by children because of his love and affection for them.

C V Pradeep

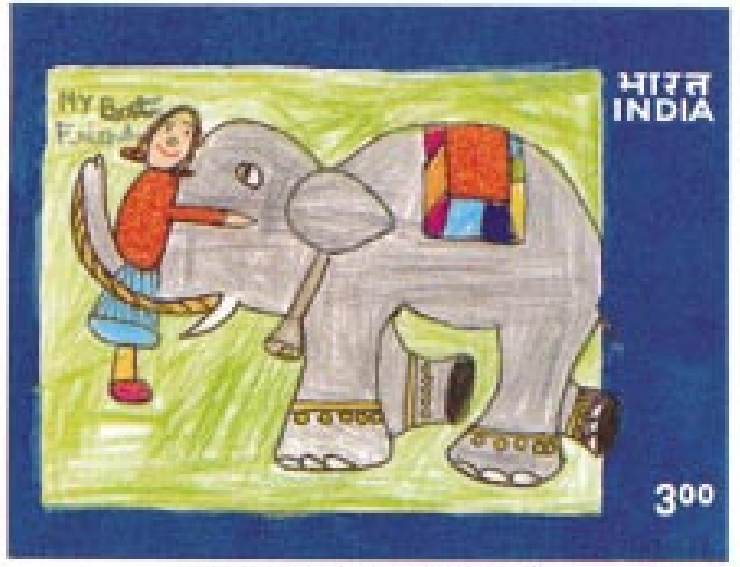

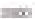

जाल दिवस 2060 CHL DeeNs DaY

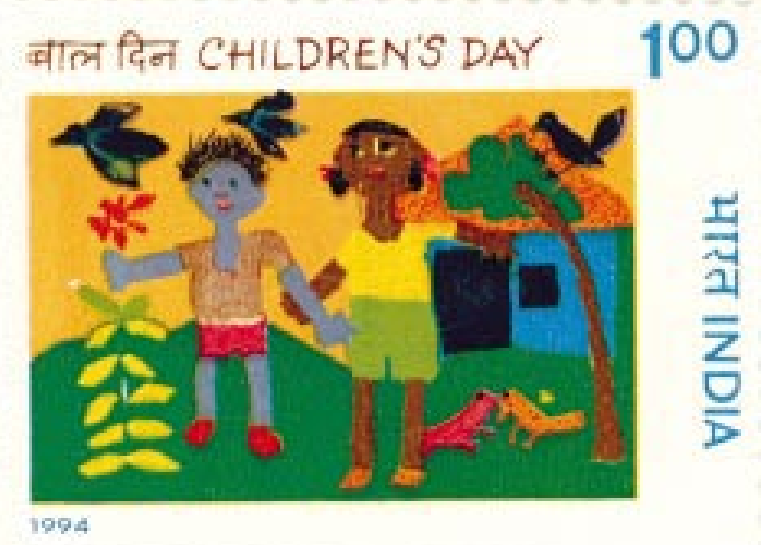

